\title{
Acoustic resonance and plasma depletion detected by GPS total electron content observation after the 2011 off the Pacific coast of Tohoku Earthquake
}

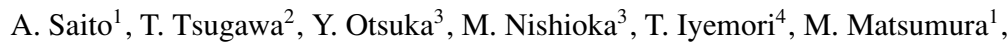 \\ S. Saito ${ }^{5}$, C. H. Chen ${ }^{1}$, Y. Goi ${ }^{1}$, and N. Choosakul ${ }^{6}$ \\ ${ }^{1}$ Department of Geophysics, Kyoto University, Japan \\ ${ }^{2}$ National Institute of Information and Communications Technology, Japan \\ ${ }^{3}$ Solar-Terrestrial Environment Laboratory, Nagoya University, Japan \\ ${ }^{4}$ Data Analysis Center for Geomagnetism and Space Magnetism, Kyoto University, Japan \\ ${ }^{5}$ Electronic Navigation Research Institute, Japan \\ ${ }^{6}$ Rajamangala University of Technology, Thanyaburi, Thailand
}

(Received April 7, 2011; Revised May 24, 2011; Accepted June 22, 2011; Online published September 27, 2011)

\begin{abstract}
Two-dimensional structures of the ionospheric variations generated by the acoustic resonance between the ground surface and the lower thermosphere was observed for the first time near the epicenter after the $M 9.0$ Tohoku earthquake on March 11, 2011. A short-period oscillation of total electron content was observed by a GPS receiver array after the earthquake for four hours in the vicinity of the epicenter. It was centered in the east of the epicenter where the tsunami was estimated to commence. The frequency of the dominant mode of the oscillation was $4.5 \mathrm{mHz}, 222$ seconds of period, while there were minor oscillations whose frequency were $3.7 \mathrm{mHz}$ and $5.3 \mathrm{mHz}$. These periods are consistent with the periods of the acoustic resonance between the ground surface and the lower thermosphere, predicted by a numerical model. The amplitude of the TEC oscillation showed a gradual change of the amplitude. The two-dimensional distributions of TEC variations generated by this resonance had wave frontal structures that extended from northwest to southeast. The resonant oscillation of the TEC was accompanied by a depletion of TEC whose duration was about 60 minutes. The area of this depletion also centered on the epicenter.
\end{abstract}

Key words: Ionosphere, earthquake, GPS, TEC, acoustic resonance.

\section{Introduction}

The acoustic resonance between the ground surface and the lower thermosphere has been studied for a few decades (e.g., Jones and Georges, 1976; Tahira, 1995). The atmospheric acoustic waves that are generated by lithospheric and tropospheric phenomena propagate vertically. Some of these waves reflect downward in the lower thermosphere, and interfere with the upward propagating waves. This interference makes the modal resonance between the ground surface and the lower thermosphere at frequencies of 3$5 \mathrm{mHz}$ (Tahira, 1995). Some part of the resonant wave leaks upward and generates ionospheric variations at these resonant frequencies (Shinagawa et al., 2007).

Iyemori et al. (2005) observed a geomagnetic field oscillation after the Sumatra 2004 earthquake. They concluded that the magnetic field oscillation was generated by acoustic waves in the electric current region, at an altitude of about $100 \mathrm{~km}$. Choosakul et al. (2009) reported a periodic fluctuation of total electron content (TEC) measured by a GPS receiver network after the Sumatra 2004 earthquake. It had

Copyright (c) The Society of Geomagnetism and Earth, Planetary and Space Sciences (SGEPSS); The Seismological Society of Japan; The Volcanological Society of Japan; The Geodetic Society of Japan; The Japanese Society for Planetary Sciences; TERRAPUB.

doi: $10.5047 /$ eps.2011.06.034 a clear periodicity at $3.7 \mathrm{mHz}$ and $4.4 \mathrm{mHz}$, and continued for more than three hours in the vicinity of the epicenter. Shinagawa et al. (2007) explained that the oscillation was caused by the resonance of the acoustic waves that propagated vertically between the ground surface and the lower thermosphere. The resonance is predicted to be limited to the vicinity of the source region, because it was established by the vertical reflection of the acoustic wave. Besides the periodic fluctuation, several types of ionospheric variations after earthquakes have been reported (e.g., Afraimovich et al., 2001; Heki and Ping, 2005; Otsuka et al., 2006; Astafyeva and Heki, 2009).

After the 2011 off the Pacific coast of Tohoku Earthquake on March 11, 2011, in Japan, various types of ionospheric variations were observed around Japan. The outline of the variations and the propagating structures in the wide area have been discussed by Tsugawa et al. (2011) and Chen et al. (2011). This paper focuses on the ionospheric variations in the vicinity of the epicenter. In the ionosphere over the vicinity of the epicenter, a periodic oscillation and depletion of TEC were observed by GPS receivers. The frequency implies that this oscillation was generated by the acoustic resonance. The two-dimensional structures of the ionospheric variations generated by this acoustic resonance were observed for the first time by the high-resolution observation 
of a GPS network. The two-dimensional structures of the TEC depletion after earthquakes were also observed for the first time.

\section{Observation}

An intense earthquake occurred at 05:46:23 UT on March 11, 2011 (US Geological Survey, 2011). Its epicenter was at $\left(38.32^{\circ} \mathrm{N} ; 142.37^{\circ} \mathrm{E}\right)$, and its moment magnitude was 9.0. TEC data were derived from the GPS data of GEONET-a GPS receiver array network operated by the Geospatial Information Authority, Japan. The sampling rate of GEONET is $1 \mathrm{~Hz}$. The number of available GEONET receivers on March 11, 2011, was 1,230. The total electron content data along the GPS radio wave path between the groundbased receivers and the GPS satellites were derived from the pseudo-ranges and phases of the dual-frequency GPS radio waves (Saito et al., 1998). The instrumental biases of the satellites and the receivers were estimated and subtracted from the observed data by the method of Otsuka et al. (2002). An outline of the ionospheric variations detected by GEONET after the 2011 off the Pacific coast of Tohoku Earthquake has been given by Tsugawa et al. (2011), and the ionospheric variations that propagated over a long distance were studied by Chen et al. (2011).

\section{Results}

The time series of the slant-TEC data observed by the "950272" GPS station with a radio signal from the PRN26 satellite is shown in Fig. 1. The slant-TEC data is the observed TEC data without any conversions except for the subtraction of instrumental biases. The period of the data is from 05:15 to 07:15 UT on March 11, 2011. The location of the receiver was $\left(36.13^{\circ} \mathrm{N} ; 138.46^{\circ} \mathrm{E}\right)$. The location where the satellite-receiver path crossed the ionospheric altitude, $300 \mathrm{~km}$, was $\left(37.95^{\circ} \mathrm{N} ; 142.46^{\circ} \mathrm{E}\right)$ at 06:00 UT, and $\left(36.78^{\circ} \mathrm{N} ; 147.40^{\circ} \mathrm{E}\right)$ at $07: 00 \mathrm{UT}$. The location of the observational point at $06: 24 \mathrm{UT}$ is represented by a plus mark at $\left(37.73^{\circ} \mathrm{N} ; 144.06^{\circ} \mathrm{E}\right)$ in Fig. 5. During this period, the observational point moved to the southwest, and the elevation angle of the satellite-receiver path kept decreasing. This is the reason why the slant-TEC shows a linear increase before 6:56 UT.

The earthquake occurred at $05: 46: 23 \mathrm{UT}$ at $\left(38.32^{\circ} \mathrm{N}\right.$; $142.37^{\circ} \mathrm{E}$ ) (US Geological Survey, 2011). The first arrival of a co-seismic ionosphere perturbation detected by GEONET was at 05:53:22 UT by the "950158" station and the PRN05 satellite. The TEC data observed from "950272" and PRN26 showed an impulsive increase, whose amplitude was larger than 3 TEC units about ten minutes after the earthquake. One TEC unit is $10^{16}$ electron $/ \mathrm{m}^{2}$. After the impulsive increase, the TEC showed a depletion around 06:00 UT, whose amplitude was about 4 TEC units. Otsuka et al. (2006) observed a similar depletion of TEC after the 2004 Sumatra earthquake though it was not specifically discussed in their paper. In their figures 1 and 3, a TEC depletion whose amplitude was larger than 5 TEC units is seen.

Besides the impulsive increase and the depletion of the TEC, periodic variations of TEC were seen in Fig. 1, with large amplitudes from 05:58 to 06:40 UT. The peak-topeak amplitude was about 2 TEC units. Their period was

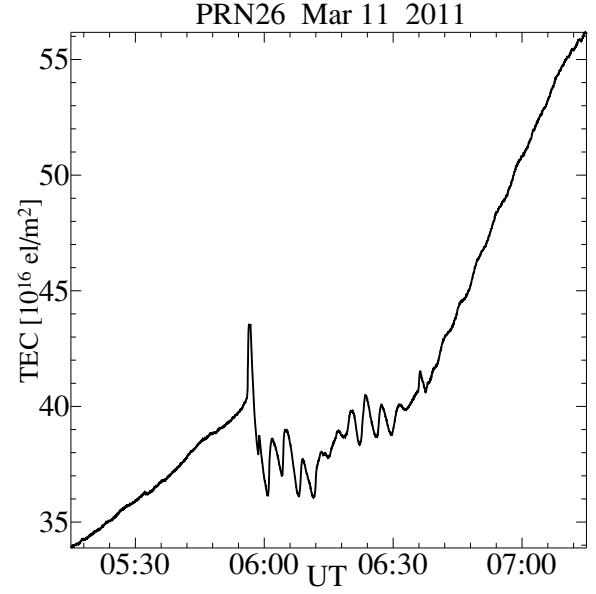

Fig. 1. Time series of the slant-TEC data observed by the "950272" station of GEONET from 05:15 to 07:15 UT on March 11, 2011, with the signal from the PRN26 satellite. The earthquake occurred at 05:46:23 UT.

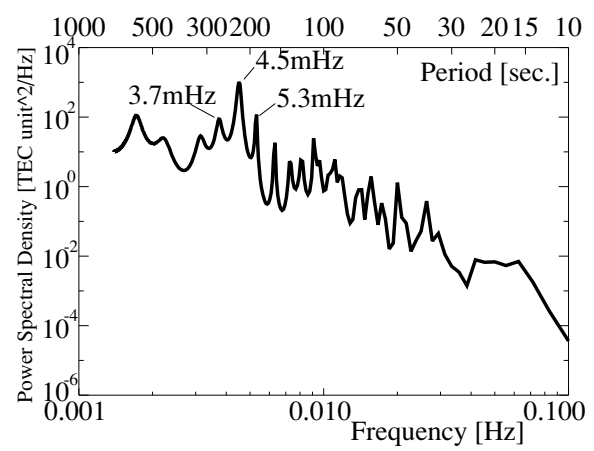

Fig. 2. Spectrum of the TEC data observed by the "950272" station with PRN 26 from 06:00 UT to 06:40 UT on March 11, 2011.

about 4 minutes. The amplitude of the oscillation showed a gradual change, and two wave packets were formed around 06:05 and 06:27 UT. After 06:40 UT, the amplitude became small.

The spectrum of the TEC data from the "950272" GPS station and the PRN26 satellite is shown in Fig. 2. The horizontal axis shows the frequency from $1 \mathrm{mHz}$ to $100 \mathrm{mHz}$. The spectrum was calculated from the data between 06:00 and 06:40 UT using a maximum entropy method. The lag of the calculation was 720 seconds. A dominant peak is seen at 222 seconds, $4.5 \mathrm{mHz}$. There are two minor peaks at 188 seconds, $5.3 \mathrm{mHz}$, and 268 seconds, $3.7 \mathrm{mHz}$. There is another minor peak at low frequency, 582 seconds, $1.7 \mathrm{mHz}$.

The high-pass filtered TEC data whose cut-off period is 10 minutes is displayed in Figs. 3(a) and (b). This cut-off period was selected to study the characteristics of the TEC oscillation shown in Figs. 1 and 2. The high-pass filtered data were converted to the vertical TEC assuming the electron is concentrated in a thin shell at $300 \mathrm{~km}$ altitude. To derive the horizontal map of the TEC variations, the TEC data inside grids, measuring 0.15 degrees in longitude and 0.15 degrees in latitude, were averaged. This procedure is similar to that used in Saito et al. (1998) except for the cutoff period. The grid TEC data was smoothed between nearby 

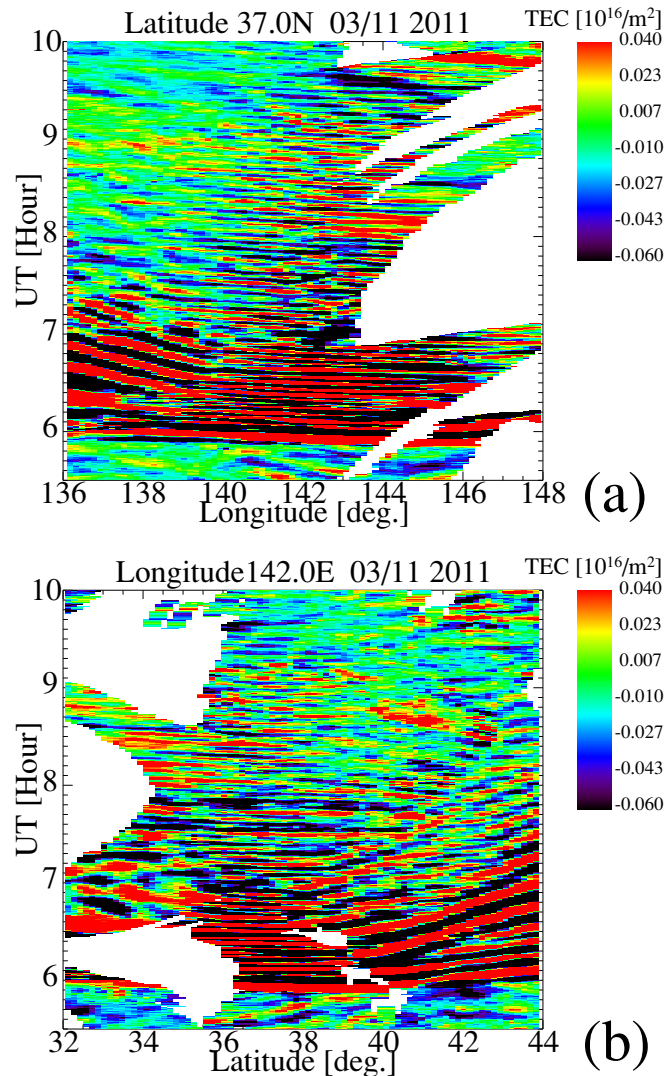

Fig. 3. The high-pass filtered TEC data whose cut-off period is 10 minutes (a) along $37^{\circ} \mathrm{N}$ latitude from $136^{\circ} \mathrm{E}$ to $148^{\circ} \mathrm{E}$, and (b) along $142^{\circ} \mathrm{E}$ longitude from $32^{\circ} \mathrm{N}$ to $44^{\circ} \mathrm{N}$ from $05: 30$ to $10: 00 \mathrm{UT}$.

grids to fill data gaps.

Figure 3(a) shows the high-pass filtered TEC data along $37^{\circ} \mathrm{N}$ latitude from $136^{\circ} \mathrm{E}$ to $148^{\circ} \mathrm{E}$ from $05: 30$ to $10: 00 \mathrm{UT}$. The vertical axis shows the time, with time going from bottom to top. After 06:00 UT, TEC variations were seen in the entire longitudinal range. After that, structures with a slow propagation velocity are seen at longitudes more westward than $139^{\circ} \mathrm{E}$ from 06:00 to 08:00 UT. These propagating structures had circular wave fronts, and propagated in the radial direction. Details of these wave fronts are discussed in another an accompanying paper (Tsugawa et al., 2011). At longitudes more eastward than $139^{\circ} \mathrm{E}$, a periodic oscillation of TEC is seen from 06:00 to 09:45 UT. The amplitude was the largest between 06:00 and 07:00 UT. This oscillation corresponds to the TEC oscillation after the earthquake, which is seen in Fig. 1. Because there is a small number of GPS receivers of GEONET in the eastward area, there are many gaps in the TEC data.

Figure 3(b) shows the high-pass filtered TEC data along $142^{\circ} \mathrm{E}$ longitude from $32^{\circ} \mathrm{N}$ to $44^{\circ} \mathrm{N}$ from $05: 30$ to 10:00 UT. At higher than $40^{\circ} \mathrm{N}$, the slow propagation structures are seen. Below $38^{\circ} \mathrm{N}$, the periodic oscillation is seen from 06:00 to 09:15 UT. As seen in Fig. 3(a), the amplitude was the largest through 07:00 UT. Although there are large data gaps in the low latitude region, it is seen that the oscillation had a small amplitude at latitudes lower than $36^{\circ} \mathrm{N}$.

It was observed that the TEC oscillation propagated horizontally. Figure 4 shows a close-up of a portion of the data

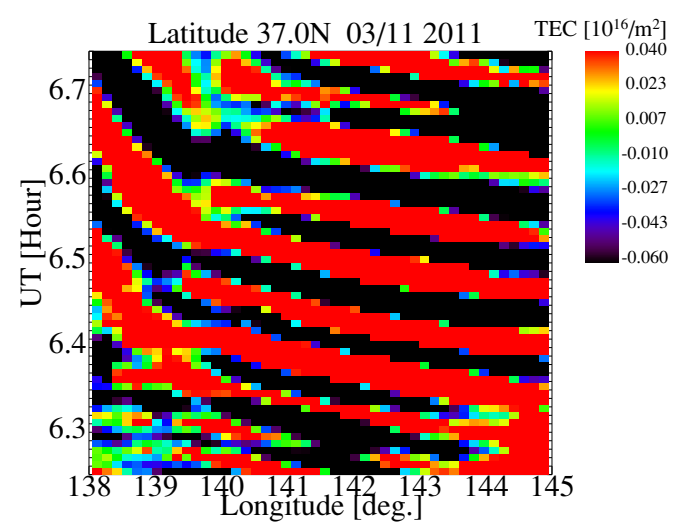

Fig. 4. Same as Fig. 3(a) for the TEC data along $37.0^{\circ} \mathrm{N}$ from $138^{\circ} \mathrm{E}$ to $145^{\circ} \mathrm{E}$ from $06: 15$ to $06: 45 \mathrm{UT}$.

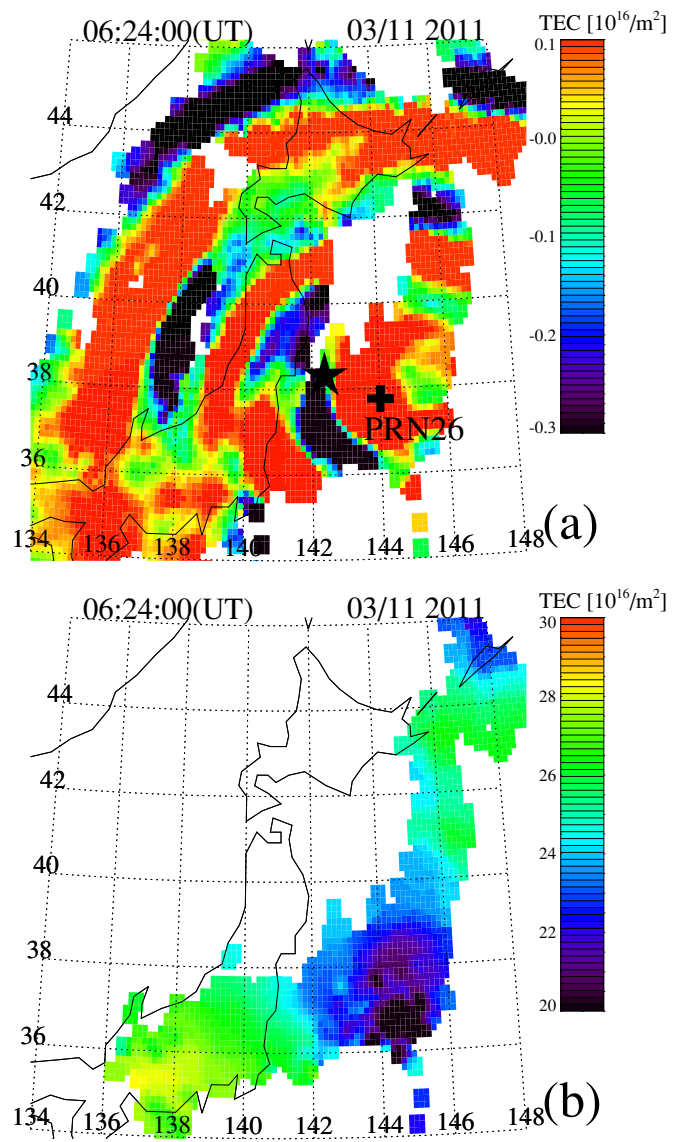

Fig. 5. Two-dimensional map of (a) the high-pass filtered TEC data and (b) the non-filtered TEC data from $134^{\circ} \mathrm{E}$ to $148^{\circ} \mathrm{E}$, and from $34^{\circ} \mathrm{N}$ to $48^{\circ} \mathrm{N}$ at 06:24 UT on March 11, 2011. The star mark represents the location of the epicenter. The plus mark represents the observational points of the "950272" station and PRN26 at 06:24 UT.

shown in Fig. 3(a). It shows the high-pass filtered TEC data along $37.0^{\circ} \mathrm{N}$ from $138^{\circ} \mathrm{E}$ to $145^{\circ} \mathrm{E}$ from $06: 15$ to $06: 45 \mathrm{UT}$. The features of the TEC variations can be seen to be different in the western area and the eastern area of this figure. In the western area, the propagation velocities of the variations were small. In the eastern area, there were variations with short periods and high propagation velocities. This short-period structure propagated westward with a velocity 
of about $2.2 \mathrm{~km} / \mathrm{s}$. From the two-dimensional observation, the phase velocity is estimated to be $1.4 \mathrm{~km} / \mathrm{s}$ to the southwest direction. These velocities were estimated by tracking the wavefront assuming the temporal change of the horizontal structure is negligible.

The two-dimensional map of the high-pass filtered TEC data and the non-filtered TEC are shown in Figs. 5(a) and (b), respectively. The data cover the region from $134^{\circ} \mathrm{E}$ to $148^{\circ} \mathrm{E}$, and from $34^{\circ} \mathrm{N}$ to $48^{\circ} \mathrm{N}$ at $06: 24 \mathrm{UT}$ on March 11, 2011. Two circular wave fronts are seen at $\left(40^{\circ} \mathrm{N}\right.$; $\left.136^{\circ} \mathrm{E}\right)$, and $\left(40^{\circ} \mathrm{N} ; 140^{\circ} \mathrm{E}\right)$. These wave fronts correspond to the slow-propagation structures shown at a longitude further west than $142^{\circ} \mathrm{E}$ in Figs. 3(a) and 4, and at latitudes higher than $40^{\circ} \mathrm{N}$ in Fig. 3(b). Inside these circular wave fronts, there are two enhancements whose wave front extends from northwest to southeast at $\left(37^{\circ} \mathrm{N} ; 141^{\circ} \mathrm{E}\right)$, and $\left(38^{\circ} \mathrm{N} ; 144^{\circ} \mathrm{E}\right)$. They traveled in a southwest direction with a propagation velocity of $1.4 \mathrm{~km} / \mathrm{s}$.

Non-filtered TEC data at 06:24 UT observed with the PRN26 satellite in Fig. 5(b) show a depletion of the ionospheric plasma around the epicenter. The amplitude of the depletion was larger than 5 TEC units. The horizontal size of the area where the depletion was observed was about $500 \mathrm{~km}$. As seen in Fig. 1, the TEC depletion commenced sharply after the earthquake, and recovered gradually in one hour.

\section{Discussion}

A periodic oscillation of the ionospheric plasma was detected by GPS-TEC observations above the epicenter after the 2011 Tohoku earthquake at $\left(38.32^{\circ} \mathrm{N} ; 142.37^{\circ} \mathrm{E}\right)$. It started about 7 minutes after the earthquake, and continued for four hours. The oscillation was detected in the region from $35^{\circ} \mathrm{N}$ to $39^{\circ} \mathrm{N}$, and from $139^{\circ} \mathrm{E}$ to $146^{\circ} \mathrm{E}$. The period and frequency of the oscillation detected by a single satellite and receiver pair were 220 seconds and $4.5 \mathrm{mHz}$, respectively. The TEC variations showed wave-frontal structures extending from northwest to southeast, which propagated in the southwest direction with a phase velocity of $1.4 \mathrm{~km} / \mathrm{s}$. The frequency and region of the ionospheric oscillation is consistent with that predicted by numerical models of acoustic resonance between the ground surface and the lower thermosphere (Shinagawa et al., 2007; Matsumura et al., 2011). It can be interpreted that the atmospheric waves were generated by the sea-surface movement caused by the earthquake, and propagated upward in the acoustic mode to the thermosphere. The wave was reflected around $100 \mathrm{~km}$ altitude because of the large vertical gradient of the neutral temperature. The reflected wave generated the acoustic resonance between the ground surface and the lower thermosphere. The reflection at the lower thermosphere is not perfect. A portion of the wave penetrates the thermosphere, and modulates the ionospheric plasma.

The long duration of the GPS-TEC oscillation after the 2011 Tohoku earthquake was similar to that observed after the Sumatra 2004 earthquake (Choosakul et al., 2009). During the first one hour, the oscillation was accompanied by ionospheric waves that traveled in a radial direction. The oscillation continued for four hours above the epicenter region. This indicates that the resonance continued for four hours after the earthquake, and the damping caused by the leakage of the wave was small at the reflection point.

When the acoustic wave propagates vertically, the wave front of the acoustic wave is almost horizontal above the source region. The wind inside such an acoustic wave moves the ionized atmosphere vertically if the geomagnetic field line effect is ignored, or in the region where the geomagnetic field is vertical. The vertical motion of the electron does not change the vertical integration of the electron, the TEC, if the recombination of plasma is assumed to be small. The existence of the horizontal structure of the TEC in the acoustic resonant region indicates that the effect of the geomagnetic field, the tilt of the ionosphere, and the recombination of plasma, should be taken into account to discuss the ionospheric variations observed by GPS. Further detailed analysis is necessary to discuss the relation between the acoustic wave and the TEC variations.

The amplitude of the TEC oscillation after the earthquake above the epicenter showed a gradual increase and decrease. As seen in Fig. 1, there were wave-packet structures that consisted of three or four waves. This is consistent with the numerical model by Matsumura et al. (2011). Although there were several aftershocks of the earthquakes, no significant change of TEC was detected associated with the aftershocks. We concluded that the amplitude change was not generated by the aftershocks but the coupling of the modes of the acoustic resonance.

The region where the oscillation was detected was from $35^{\circ} \mathrm{N}$ to $39^{\circ} \mathrm{N}$, and from $139^{\circ} \mathrm{E}$ to $146^{\circ} \mathrm{E}$. This is larger than the size of the area where the plate shifted. Although the acoustic resonance is caused by the vertical propagation of the acoustic wave, it can occur with the wave that propagates in the off-zenith direction. This is also consistent with the two-dimensional model calculation by Matsumura et al. (2011).

A depletion of TEC was observed in the vicinity of the epicenter as seen in Fig. 5(b). This depletion was not observed in areas away from the epicenter. The mechanism of this depletion has not been clarified. The verticalpropagating acoustic wave changes the density of the neutral atmosphere. In the high-density phase, the rate of plasma recombination increases, and the plasma density decreases. In the low-density phase, the recombination reduces, but the plasma density cannot increase to fill the depletion. This process could cause depletion of the TEC. A quantitative discussion is necessary to assess these mechanisms.

\section{Summary}

In the vicinity of the epicenter, two-dimensional structures of the ionospheric variations generated by acoustic resonance between the ground surface and the lower thermosphere were observed for the first time by a GPS receiver array network after the $M 9.0$ Tohoku earthquake on March 11, 2011. A short-period oscillation of TEC was detected for four hours near the epicenter. It centered in the east of the epicenter where the tsunami was estimated to commence. The frequency of the dominant mode of the oscillation was $4.5 \mathrm{mHz}, 222$ seconds of period, while there were minor oscillations whose frequencies were $3.7 \mathrm{mHz}$ 
and $5.3 \mathrm{mHz}$. These periods are consistent with the periods of acoustic resonance between the ground surface and the lower thermosphere, predicted by a numerical model. The resonant oscillation of the TEC was accompanied by depletion of the TEC whose duration was longer than 60 minutes. This is the first two-dimensional imaging observation of ionospheric variations in the vicinity of the epicenter after an intense earthquake.

Acknowledgments. GPS data of GEONET was provided by Geospatial Information Authority, Japan.

\section{References}

Afraimovich, E. L., N. P. Perevalova, A. V. Plotnikov, and A. M. Uralov, The shock-acoustic waves generated by the earthquakes, Ann. Geophys., 19, 395-409, 2001.

Astafyeva, E. and K. Heki, Dependence of waveform of near-field coseismic ionospheric disturbances on focal mechanisms, Earth Planets Space, 61, 939-943, 2009.

Chen, C. H., A. Saito, C. H. Lin, J. Y. Liu, H. F. Tsai, T. Tsugawa, Y. Otsuka, M. Nishioka, and M. Matsumura, Long-distance propagation of ionospheric disturbance generated by the 2011 off the Pacific coast of Tohoku Earthquake, Earth Planets Space, 63, this issue, 881-884, 2011.

Choosakul, N., A. Saito, T. Iyemori, and M. Hashizume, Excitation of 4-min periodic ionospheric variations following the great Sumatra-Andaman earthquake in 2004, J. Geophys. Res., 114, A10313, doi:10.1029/2008JA013915, 2009.

Davies, K. and D. M. Baker, Ionospheric effects observed around the time of the Alaskan earthquake of March 28, 1964, J. Geophys. Res., 70, 2251-2253, 1965.

Heki, K. and J. S. Ping, Directivity and apparent velocity of the coseismic ionospheric disturbances observed with a dense GPS array, Earth Planet. Sci. Lett., 236, 845-855, 2005.

Iyemori, T., M. Nose, D. Han, Y. Gao, M. Hashizume, N. Choosakul, H. Shinagawa, Y. Tanaka, M. Utsugi, A. Saito, H. McCreadie, Y.
Odagi, and F. Yang, Geomagnetic pulsations caused by the Sumatra earthquake on December 26, 2004, Geophys. Res. Lett., 32, L20807, doi:10.1029/2005GL024083, 2005.

Jones, R. M. and T. M. Georges, Infrasound from convective storms, Part III. Propagation to the ionosphere, J. Acoust. Soc. Am., 59, 765-779, 1976.

Matsumura, M., A. Saito, T. Iyemori, H. Shinagawa, T. Tsugawa, Y. Otsuka, M. Nishioka, and C. H. Chen, Numerical simulations of atmospheric waves excited by the 2011 off the Pacific coast of Tohoku Earthquake, Earth Planets Space, 63, this issue, 885-889, 2011.

Otsuka, Y., T. Ogawa, A. Saito, T. Tsugawa, S. Fukao, and S. Miyazaki, A new technique for mapping of total electron content using GPS network in Japan, Earth Planets Space, 54, 63-70, 2002.

Otsuka, Y., N. Kotake, T. Tsugawa, K. Shiokawa, T. Ogawa, Effendy, S. Saito, M. Kawamura, T. Maruyama, N. Hemmakorn, and T. Komolmis, GPS detection of total electron content variations over Indonesia and Thailand following the 26 December 2004 earthquake, Earth Planets Space, 58, 159-165, 2006.

Saito, A., S. Fukao, and S. Miyazaki, High resolution mapping of TEC perturbations with the GSI GPS network over Japan, Geophys. Res. Lett., 25, 3079-3082, 1998.

Shinagawa, H., T. Iyemori, S. Saito, and T. Maruyama, A numerical simulation of ionospheric and atmospheric variations associated with the Sumatra earthquake on December 26, 2004, Earth Planets Space, 59, 1015-1026, 2007.

Tahira, M., Acoustic resonance of the atmosphere at $3.7 \mathrm{mHz}$, J. Atmos. Sci., 52(15), 2670-2674, 1995.

Tsugawa, T., A. Saito, Y. Otsuka, M. Nishioka, T. Maruyama, H. Kato, T. Nagatsuma, and K. T. Murata, Ionospheric disturbances detected by GPS total electron content observation after the 2011 off the Pacific coast of Tohoku Earthquake, Earth Planets Space, 63, this issue, 875879, 2011.

U.S. Geological Survey, http://earthquake.usgs.gov/, 2011.

A. Saito (e-mail: saitoua@kugi.kyoto-u.ac.jp), T. Tsugawa, Y. Otsuka, M. Nishioka, T. Iyemori, M. Matsumura, S. Saito, C. H. Chen, Y. Goi, and N. Choosakul 